\title{
Black Hole Suns: Binarism and Gravity in Cultural Fields
}

\author{
By Alison Gerber
}

\begin{abstract}
Sociologicial analyses of artistic practice have long drawn on theoretical traditions grounded in binaries and dualisms. Such analytical strategies, exemplified here by field theoretical approaches, center art objects and their movements in and across markets, where binaristic visions of art worlds do offer significant leverage. But when the analyst moves away from markets for art objects and looks to artistic practices the binaristic lens provides, at best, a blurred image with meaningful blind spots. This article suggests an alternative vision of artistic practice -one based on gravity rather than polarity-that captures the ways individuals and their actions make sense in a specific universe of meaning without forcing them into fundamentally competitive and economistic relationships. It leverages findings enabled by a unique sampling strategy in a four year study of visual artists in the United States to illuminate some limitations of binary theoretical frameworks, and outlines a generative alternative to dualism that promotes new analytical and theoretical directions for sociological analyses of artists and artistic practice. This alternative model provides new leverage on four persistent issues in analyses of artistic work: cultural change in occupational fields; actors' attempts to manage overlapping but incommensurate forms of recognition, reputation, attention, and success; the persistent hegemony of markets for objects in both vernacular and sociological understandings of artistic practice; and questions of visibility and legitimacy central to understanding boundary formation and boundary work in creative fields. The gravitational metaphor promotes a distict set of strategies for the study of artistic work as well as other nontraditional occupations.
\end{abstract}

Keywords: Sociology of the arts, artistic practice, social theory, Bourdieu, binarism and duality, diagrammatic theorizing.

Gerber, Alison: "Black Hole Suns: Binarism and Gravity in Cultural Fields", Culture Unbound, Volume 20, Issue 2, 2020: 393-411. Published by Linköping University Electronic Press: http://www.cultureunbound.ep.liu.se 


\section{Introduction}

Binarism has been core to the sociological analysis of art and artists across varied theoretical traditions, including field-theoretical, ecological, and post-structuralist approaches. Dualistic traditions accompany and reinforce a widespread emphasis in such analyses on art objects and their movements in and across markets -an emphasis that goes so far as to treat artists' activities and artists themselves as objects for public consumption. But however well this model may describe the market positions of some art objects, its analytical leverage on the broader art field-one made up of diverse multiple and overlapping art worlds populated by artists who only sometimes make those objects, and only sometimes for that market-is today lacking. This article asks whether alternatives to binarism can offer new leverage in understanding artistic practices and artists' identities. It suggests that the emphasis on polarity at the heart of traditional sociological analyses could fruitfully be supplemented with an alternative model relying on a very different force: gravity.

This article considers what we might gain by looking beyond binarism in our analyses of artistic practice. It draws on findings from a four-year qualitative study of visual artists in the United States and exploits that study's unique sampling methodology to consider persistent empirical and analytical issues that are not well served by analysts' baseline presumptions of binaries underlying social life. Finally, the article proposes an alternative model that might allow for fruitful and generative analyses. This model promotes new approaches and allows for new insights in the study of artistic activity and artistic identities.

The model proposed here offers allows analysts interested in artistic practices (rather than art objects and their movements through markets) to make sense of cultural change in artistic communities; related but incommensurate forms of recognition, reputation, attention, and success; and dynamic standards driving visibility and legitimacy in creative work. It shows how and when artworks, artistic practices, and artists' identities can be disentangled, and provides a model to complement visions of art worlds that rely on polar forces and that center markets for artistic objects in their analyses. The model outlined here, using gravity as its basic metaphor, promotes an emphasis on artistic practices and attention to a dynamic universe of meaning where those practices are made legible.

\section{Literature}

Sociological analyses of the arts are often underpinned by binaristic models of value and a tightly linked attention to art objects, framing artistic practices and artistic identities as legible primarily in terms of their relationships to those objects and values. Visions of art worlds dominated by dualisms (embodied for 
the purposes of this discussion by the Bourdieusian field, as discussed below) are excellent theoretical tools for understanding the movements, meanings, and value of art objects in markets. The economism at the heart of field-theoretical models of cultural fields is well documented, though authors often specify their focus on economic activities not as market activity but in more general terms like "competition" or "domination" (Abbott 2005, Bourdieu 1993). But however well this model may describe the market positions of some art objects, its analytical leverage on the broader art field is today lacking.

Centering objects presents problems for at least two kinds of analyses. For those concerned specifically with artistic careers and incomes, the vast majority of artists in the US neither structure their lives around a winner-take-all market nor an economic-world-reversed; rather, they live in an economic world obverse, one where both sides of the coin are visible at all times and careers are made through purposeful and agentic movement through multiple markets (Gerber \& Childress 2017b). For those interested in artistic and creative practices both within and beyond artistic careers, the issues of an object-centered view are even more obvious, even for analysts who retain a concern for value and valuation. Such an object-centered view of artistic work (in which salable artistic objects like sculptures and book manuscripts are the only legitimate outcomes and legible elements of artistic labor-an emphasis that goes so far as to treat artists' activities and artists themselves as objects for public consumption) neglects the vast majority of activities that compose contemporary arts practices. Unless we define artists narrowly as "people who make a living selling art objects," no useful definition of the visual artist involves a majority of people making a living through gallery sales, and by most definitions it's a very small minority (Gerber \& Childress 2017a). An economistic, object-centered view neglects the vast majority of activities that compose contemporary arts practices.

This article takes the Bourdieusian vision of cultural fields as its foil, since it is both a powerful tool for some kinds of analyses and is a central perspectiveeven hegemonic-in contemporary sociologies of the arts, and thanks to its tight fit to vernacular understandings of art worlds. ${ }^{1}$ Generally, these analyses imagine cultural fields to be competitive arenas in which actors' dispositions towards cultural objects are determined by those actors' class status, and where position-taking by actors serves to consecrate particular kinds of objects. Bourdieu was concerned with the emergence of the work of art as a commodity and the related development of an alternative to commodity markets in the possibility of "art for art's sake" (Bourdieu 1983). In his formulation, cultural fields are bifurcated into a polar system, with two competing and contradictory sets of rules, stakes, and values. On the one side (the heteronomous pole), market forces drive status, power, and success; sell more tickets to your film, here, and the force 
of the sales numbers exerts its own authority. On the other side (the autonomous pole), the value of art is judged by producers themselves; in an art-for-art's sake realm, it's the critic and the fellow-artist whose voice matters in awarding acclaim, power, and consecration. The metaphor of the two poles, since they encompass competing value-systems, promotes an electromagnetic vision of social forces. Artists, viewers, and art objects themselves push ever farther away from one another and towards a kind of singular purity: "the duality of the principles of hierarchization means that there are few fields (other than the field of power itself) in which the antagonism between the occupants of the polar positions is more total" (Bourdieu 1983: 327). The binarism at the heart of the Bourdieusian field is not incidental, but structures contemporary uses of the theory: witness the vast literature focused on the ways that features clustered at the far end of one pole symbolically "pollute" actors and objects aiming for consecration on an opposite pole (e.g. Heise \& Tudor 2007, Solaroli 2016). Nor is the focus on art objects simply circumstantial. The apparent solidity and relative stability of objects have made them the ideal articles of analysis for these studies, allowing the observer to rank-order and categorize an array of objects as a window into messier and less durable social interactions.

Contemporary sociological theory shows concern about the all-encompassing claims of dualistic theories (e.g Mears 2011, Stark 2009, Thornton, Ocasio, \& Lounsbury 2012, Zelizer 2011), and qualitative studies focused on artistic practice find that such practices are only intermittently and problematically oriented to artistic objects (Blanco, Schuppert \& Lange 2015, Klett \& Gerber 2014, Lindström 2017, Lund 2013, Scarborough 2017, Schwarz 2016, Wohl 2015: 201). The real-world applicability and leverage offered by binary distinctions between (for instance) autonomous and economic values remains a question for many researchers, and it should be clear that a focus on art objects as the primary proxy for artistic practice is incomplete at best and, at worst, profoundly misleading. Sociologists have long questioned the degree to which Bourdieu's theorizing can be applied wholesale to new contexts (Hesmondhalgh 2006; Lamont and Molnár 2002), and many now work towards unfaithful but potentially fruitful extensions of his theories (de Boise 2016; Buchholz 2016; Krause 2018); this paper takes Lamont's suggestion that, rather than revering the model laid out in Distinction and after, we take it as the generative contribution it is and use it "to think with" (Lamont 2012).

Binaristic models work well for thinking about art objects as market objects. And if you begin with art objects in your analysis of art worlds, it's not surprising that you can find a competitive, dichotomous field with all the position-taking and power plays that we find in the markets for objects. But the closer to artistic practice the researcher stands, the more they will struggle to fit dualistic, object-oriented 
theoretical models to their data, unless they avoid the messy realities of artistic practices by effectively selecting on the dependent variable-conceptualizing the relevant population and sampling frame through the very dualism that they then use to analyze art worlds.

Binarisms abound in social theory, of course; sociologies of the arts that draw, for example, on structuralist and post-structuralist approaches draw their binarism not from competitive market assumptions but from their semiotic heritage. These analyses, with their emphasis on meaning in cultural fields, show how aesthetic experience is intimately tied to moral life (Malczewski 2016), outline the ways that artistic legitimation taps into affective and meaningful foundations (McKernan 2018), and demonstrate the ways that metaphorical meaningmaking allows actors to navigate local and global markets (Kharchenkova 2018). And contemporary analyses often aim to bring interpretive methods into conversation with field-theoretical and ecological approaches (Alexander and Bowler 2018). But built as they are on a science of signs, research in this tradition has a tendency to neglect all that does not conform to the patterns of our language (Howes 2005). And the persistent focus on public discourse in these analyses of meaningmaking holds some pitfalls. In a bid for legibility, our discursive lives can be dominated by the failure-success dialectic of competition and economic logic, most especially when we speak in public (Gerber 2017); attention to public discourse often indirectly points researchers back to a focus on objects and their markets.

This paper asks whether alternatives to binarism can offer new leverage on understanding artistic practices and artists' identities. It suggests that the emphasis on polarity at the heart of traditional sociological analyses could fruitfully be supplemented with an alternative model relying on a very different force: gravity.

\section{Methods}

This paper draws on illustrations from a study using 80 in-depth interviews and participant observation fieldwork in four regionally defined art communities in the United States. The material I draw on below has been strongly influenced by a unique selection strategy, one that allowed me to speak to a far more diverse sample of artists than standard population narratives could have. For this project, I defined "visual artists" as individuals who had publicly exhibited visual artworks (e.g. painting, sculpture, and other forms shown in institutions such as museums of contemporary art such as video and performance) in the year prior to our meeting. This criteria both restricted the relevant population to those known to be practicing art by at least a small public and opened its arms wide to capture many artists that would be either excluded or simply invisible had I relied on another strategy (e.g. holding an MFA, or making a majority of one's income at art practice, 
or the more-common snowball or respondent-driven sample). I aimed in my operationalization of "exhibition" to include as many of the kinds of sites where art is shown to the public as possible, including regional and urban/rural variation: galleries and museums, to be sure, but also rural art crawls, airports, churches, municipal offices. For each of these presenting institutions, I constructed a roster of artists who had exhibited through said institution in the past year, and then narrowed the roster further to living artists either born in or living in the United States. From each roster, I then selected 5-10\% of artists at random to contact with an interview request; almost all artists contacted agreed to an interview.2

Defining visual artists in terms of practice-by having shown work publicly in the last year-allows for a sample that allows for wide variation along occupational and economic lines, among other dimensions. The sample includes extreme diversity along dimensions like occupational commitment and success in the fine arts, education, income level and type, gender, age, race, class background, and other dimensions. It includes artists working full- and part-time in organizations both in and outside the art world, as well as artists who work on a freelance basis, artists who work for themselves in many forms, and artists with no incomes. The discussions below are very likely shaped by the diversity of my sample compared to studies with simpler criteria for inclusion or exclusion. Logistically, I would not recommend others follow my lead, but I believe that my ability to make the arguments that follow relies more on my unique sampling strategy than on any other single feature of the study.

In the study I focused especially on one window into individual artists valuation of their own practices by looking at artists' narratives of investment and their expectations around returns on investment. I consider artists to be speaking of investments in their practice when they refer in one narrative (a story with a discernible beginning and end, of which there were many in each interview) to finite resources (for example, time, money, space, or energy) committed to their artistic practice, and also link such resource commitments to presumed, hoped-for, or past specific outcomes (sales, visibility, employment, the development of new skills or relationships, happiness, and so forth) of such resource commitments.

I return to this study here with a nagging question in mind: the complexity enclosed in the apparently simple statement that someone had "quit" making art. In my fieldwork I met people who told me they once had worked as artists but had now quit; artists regularly told me about friends and acquaintances who had "quit" making art during interviews. These statements were rarely as straightforward as they had seemed, and no matter how the analyst defines the category of "artist" these quitters had not always clearly abandoned the category. A practice-focused approach showed that the "quitters" had only very rarely actually stopped doing the things they had been doing: they still painted, made photographs, danced, 
made music, wrote. They went on, much as before-but what they did stopped making sense, or made a new kind of sense. Some, to all appearances, were still "artists" in every sense of the word-they made things that looked like art objects, exhibited them in art spaces, sold them to people who believed themselves to be purchasing artworks-but agreed with those who insisted that they'd "quit" making art.

These stories of artists who had quit making art came up again and again in my interviews and fieldwork. They were uncomfortable and complicated in the same way as conversations about what counted as an artist's "own work" were: that was a term that artists used over and over, but when asked to define it they squirmed, and struggled to draw lines, and told stories about change over time and about activities in relation with other activities. The issue of quitting provides an entry to the issues that underlie this article. Understanding what these artists were trying to articulate requires distinctions between artworks, artistic practices, and artists, and understanding when and how that distinction matters. It can help us to see when an emphasis on objects leads us astray and how artists themselves make meaning in a universe much more complex than the art/commerce binary that dominates both the vernacular and sociological imagination.

In the following, I very briefly outline four accounts of value that are widespread in contemporary arts practice in the visual arts in the United States, discuss the ways that these four accounts structure meaning and value within the arts field, and then move to the conceptual argument. ${ }^{3}$ The illustrations from empirical material ground the conceptual argument in a particular art world: visual arts practice in the United States. I show how binaristic models, exemplified by Bourdieu's model of cultural fields, fail to capture important features of this cosmology of value before turning to an alternative force-gravity, rather than polarity-to propose a model that foregrounds movement, interaction, tension, and historical change. In closing, I discuss potential applications of a gravity-focused approach outside of arts field and highlight the benefits of a gravitational model.

\section{Value in Artistic Practice}

Four accounts of value are widespread among artists in the United States today; these are the logics that artists draw on when they tell stories about investments -resources committed to their practice linked to specific presumed or hoped-for or past returns.

Pecuniary accounts are bottom-line, bread-and-butter accounts of value; artists talk about sales, cash money, spreadsheets. In pecuniary accounts, the time implied between investment and return is relatively short-term and specific. "Clock time”, with its attendant busyness and density (Snyder 2013), structures accounts. 
Artists regularly use numerical justifications and make on-the-fly calculations in the process of accounting for investments in pecuniary accounts. Such accounts are oriented to a commodity market - a market that trades in art objects. The logic of this commodity market dominates pecuniary accounts, such that when artists use pecuniary accounts they often fit ephemeral and nontraditional practices to such a logic-they speak of performances as "objects," for example.

Credentialing accounts can be seen when artists when artists point to teaching or commercial work, when they say they "can always teach" or use skills gained through artistic practice to occupy specific positions in the labor markets. The time implied between investment and return is long-term and uncertain, and these accounts are oriented to a labor market, where skills have value. The ideal artwork in credentialing accounts is defined by its technical superiority, and the ideal space of these accounts is the art academy. In both pecuniary and credentialing accounts we see artists entering the world of market work and paid employment as artists in ways that both make sense to artists (who have for centuries sold artworks, taught others, and applied their skills outside of art worlds) and in a world of jobs, in which selling one's products, skills, and time by the hour or by the piece are normal ways to calculate worth and value (Biernacki 1995).

Relational accounts discuss an art that aims for interpersonal and communitarian outcomes, and promote artistic practice for the benefit of society as a whole and for both artists and audiences as citizens. Relational accounts of investment and return transcend clock time, displaying instead both task-oriented and generational understandings of time. Numerical and calculative justifications do not appear, and the relevant market is unclear. These accounts are rarely legible as explanations for investments to those outside the field, though like vocational accounts they involve widely shared meanings within the field of art and are readily understood there. They are strongly rooted in art worlds but oriented to a wide public; the ideal space for these accounts is public space, and the ideal artwork is one that sparks public debate. Relational accounts point to a belief among artists that their practices are, at the very least, good for society and, at best, transformational.

Finally, vocational accounts are arguments that activities we do for love have real value, as when an artist says, "When I say time for myself, I mean time for my work". Vocational accounts often differ strongly from either pecuniary or credentialing accounts. Time is irrelevant to narratives of investment and return; it is suspended, transcendent, and has much more in common with the task oriented time described by Thompson (1967), including its lack of division between "work" and "life", than with modern, regulated clock time. The ideal space of such accounts is the home studio-domestic, but set apart from everyday life. There is no ideal artwork in vocational accounts. In fact, the outcome of artistic practice is often minimized as irrelevant. 
For the purposes of this article, we can consider each of these four accounts to be ideal types (Adams 2005). These ideal types discussed here are neither mutually exclusive nor personal traits; artists use first one, then another type of account in patterned ways when they account for the value of artistic practice. They are both time- and place-specific. As I have discussed elsewhere, they are the result of a valuation process that can be seen more generally in fields that have undergone an occupational turn, and while the process is generalizable the outcome of that process (the specific accounts of value) discussed here is specific to artistic practice in the United States at the present time. With these accounts, artists draw a landscape of value that they traverse themselves. But questions remain: how do they envision the landscape they traverse, and how do they move within the map they have drawn?

At first glance, one might imagine a dichotomy between instrumental and evaluative accounts that could be applied here-a binary to neatly divide these accounts into a cross-classification table, with the clear logical distinctions (some accounts relying on numerical justification, others eschewing them entirely) requiring us to imagine that juxtapositions between apparently incompatible accounts are mere compromises or ambiguities: temporary and fragile, rather than potentially constitutive of a field of practice (Boltanski \& Thévenot 2006; Stark 2009). But artists use such ostensibly irreconcilable accounts together regularly, and a close look shows that they do so in patterned ways to do specific things. Pecuniary and vocational accounts, for example, are used together by artists to position themselves, their practices, and their works as both serious (occupationally committed) and called-as doing it for love and for money. Only the analyst committed to the structuring power of binarism-a set of assumptions Zelizer has termed the "hostile worlds" school—can avoid seeing such discursive practices as meaningful and potentially world-making (Zelizer 2011).

One of the easiest places these can be seen is in discussions of one's "own work", where the push and pull of pecuniary and vocational accounts are central to artists' understanding of the category. The question of what counts as one's "own work" is fluid and complex in the arts, and is an issue I have considered at length elsewhere (Gerber 2017) The issue is rarely straightforward, and the careful analyst will quickly find that there is relatively little agreement between artists on what should be included in the hallowed category, and-even more disconcertingly-artists' feelings and accounts can change, with a practice considered rewarding, creative, and likely to result in one's "own work" being suddenly or retrospectively recast as "just a job" or otherwise not one's "own work". Artists do a good deal of discursive work to both legitimize what they see as their "own work", always using at least two accounts of value in concert to position such work in a particular universe of value. This is easily seen when artists are required to defend a particular artwork against 
a critic: interweaving distinct accounts to show that they aren't simply motivated by pecuniary, or credentialing, or relational, or vocational motives. Legitimacy requires a careful dance to show balance amongst these accounts. Artists do even more discursive work to delegitimize the artwork that they see as not (or no longer) "their own", intentionally using only one account of value to show how out of balance such artworks are-out of step with their understanding of the art worlds they move among. Another rich vein of these apparently contradictory narratives can be found amongst artists' talk of "quitting" and the discursive work necessary to explain that an artist that to all observers appears to be carrying on much as before has in fact "quit" artmaking, as discussed above. Understanding what these artists were trying to articulate requires distinctions between artworks, artistic practices, and artists, and understanding when and how that distinction matters. It can help us to see when an emphasis on objects leads us astray, and how artists themselves make meaning in a universe much more complex than the art/commerce binary that dominates both the vernacular and sociological imagination.

\section{Two-by-two Tables and Coordinate Planes}

As discussed above, the analyst can of course imagine a dichotomy between instrumental and evaluative accounts that could be applied to the accounts artists give, neatly slotting types into a two-by-two table. Recall that the Bourdieusian analysis imagines cultural fields as competitive arenas bifurcated into a polar system most often imagined as a coordinate plane, with the $\mathrm{x}$-axis representing a dualism between autonomous and heteronymous art representing two competing and contradictory sets of rules, stakes, and values and the $y$-axis representing consecration. Such a system allows our ideal types to exist along continua and to be mapped to understand their place and role in competitive arenas. If we adopt the Bourdieusian view, we have the added confidence that comes with a close fit to the vernacular view of the art world: a coordinate plane mapping cultural and economic capital, a dualistic model allowing for purity of orientation, focus, and identity as artists and artworks are positioned further and further out from the center along an $\mathrm{x}$-axis. Once the analyst imagines the world in terms of such polarities, it can be hard to recall other forces that might be at work. But as puzzles like the issues of one's "own work" and the complicated reality of those who had "quit" making art show, if the analyst wants to understand today's art worlds the polar model is not always the right one-at least for the analyst that hopes to understand the lives of the vast majority of artists working today, rather than the lives of a few art objects. 
Attempts to modify the Bourdieusian model show how the binarism at the heart of such models resists significant adaptation for studies that hope to encompass artistic practices and identities alongside art objects. We might begin such an exercise in diagrammatic theorizing (Silver 2018; Swedberg 2016) by simply mapping the four accounts of value discussed above onto Bourdieu's coordinate system - retaining the $\mathrm{y}$ axis but replacing the $\mathrm{x}$ with two axes, creating a sort of three-dimensional space. Here, artists populate and navigate a field in three dimensions: an octahedron with Bourdieu's y-axis running through two vertices and the center of its base.
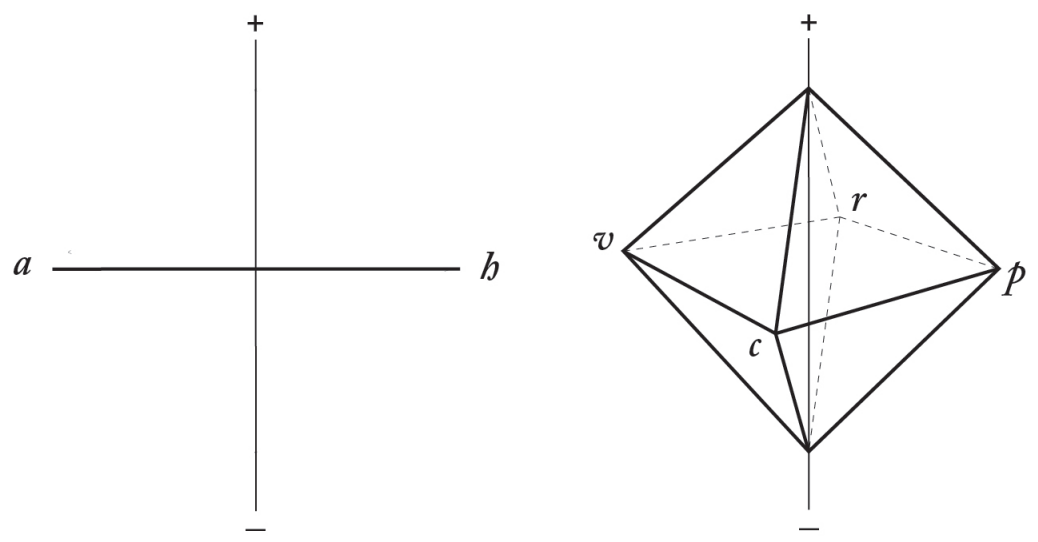

But two issues immediately arise in the attempt to fit empirical materials to this model. First, because the relationships between these $\mathrm{x}$ and $\mathrm{z}$ vertices are historically and locally dependent, those axes need to be mobile, to sometimes push together and move apart. As the analyst plots points-individual artists, particular practices-the model needs to allow for particular ideal types to be at one moment quite similar to another, at another moment diametrically opposed: at one point credentialing and vocational accounts look like polar opposites, while later they might sit in neighborly comfort, allowing for a particular way to make sense of artistic practice.

The second empirical issue came with my inability to represent a meaningful distinction between the ways artists acted in the world of practice I had seen and the way their identities, practices, and artworks moved within the provisional figure: the place and relative value of something like purity. In Bourdieu's model, an excess of autonomy-going too far down the art-for-art's sake road-is dangerous, of course, for the heteronomous-pole artist, but only solidifies the autonomous-pole artist's commitment; the only danger is to that artist's wallet. To gauge the fit between my data and the provisional model, though, it was crucial that artistic identities, practices, and artworks could negotiate two or more 
accounts of value simultaneously if they hoped for legitimacy of any kind. Both puzzles discussed above-the question of one's "own work" and artists' "quitting" -showed how poorly the notion of purity worked to structure an understanding of artistic practice.

People like to say that artists don't talk about money; we know that's not true, but we keep saying it, keep pointing to some taboo. I have argued elsewhere that when we say artists don't talk about money our thoughts are structured by a particular caricature-a soulless artist-as-speculator-and that it's only one of the caricatures that guard the boundaries of the world of legitimate contemporary art practice (Gerber 2017). The Sunday painter represents the limits of vocationalism, and the resume-building savvy of the artist too concerned with building the credentials for an illegitimate future points to another path away from legitimate practice; finally, the outer limits of relational accounts of value-too-tight friendships or obviously exploitative ones-structure artists' stories and their critiques of others. Each ideal type allows for sensemaking, but also provides an exit route; too much autonomy, then, and the artist runs the risk of "quitting" leaving (or being shut out of) the art world entirely, no matter their activities. The base's vertices don't represent goals or pure figures; they are, instead, caricaturesbogeymen that mark the boundaries of legitimate artistic practice, each of them a cautionary tale.

Alongside these two empirical problems, two more fundamental conceptual issues emerged through these attempts, both having to do with the nature of the axes in this Cartesian space. First, the ways that the vertices were labeled constrained what the model made possible; specifically, no matter how much the angles between my vertices expanded and contrasted, the model still imagined relationships in terms of dualisms; there was no way out of a static polarity. Second, adding dimensions to the coordinate model only works if we can assume that each dimension is independent-a difficult assumption given the historical and institutional forces at play in the development, dissemination, and uses of ideal types in this context. To think beyond binarism, the analyst needs to remove the architecture that constrains our view of the ways that meanings can change over time, to imagine a conceptual model that does not force ideal types into dichotomies.

Finding a way out of dualism makes it possible to imagine action taking place outside of competitive relationships and the kinds of position-taking that can model many market relationships but does not always offer traction on other kinds of activity. A path away from dualism can also make it easier to think broadly about how meanings might change over time. If we allow ideal types out of dichotomies, we allow that, for example, the vocational activities of the futurethe things we do for love-might align entirely with today's credentialing accounts. 
It's not impossible to imagine; think of today's do-what-you-love ideology, the ways it is aligned with the moral imperative to work-and then try to hold on to the belief that doing what you love and doing it for money are always and forever diametrically opposed.

Despite what I have outlined as some of the blind spots of the dualistic view, an alternative must be structured somehow; the data show that accounts of value aren't applied willy-nilly. There are, of course, patterns in the ways that these four ideal types are deployed on the ground; each is constrained by culture, history, prior use. To understand how they constitute a field of practice, the analyst might need to look beyond the two-by-two tables and coordinate planes so common in sociological theorizing and imagine new forms, with new forces at play.

\section{Black Hole Suns}

Here, I outline one such form: a gravitational model that allows the analyst to model, fit, and make sense of data that otherwise risks being discounted as epiphenomenal or trivial and, more importantly, allows the analyst to think differently, to generate new theoretical ideas and new empirical questions and to imagine new ways to answer such questions.

Using gravity as the force at play in a model offers an intuitive way out of the stable oppositions of binarism and can help us capture the ways that individuals and their actions make sense in a specific universe of meaning without forcing them into fundamentally competitive and economistic relationships. Here, imagine ideal types as four bodies orbiting one another; each one laden with meaning, the relationships between them structuring a field of practice.

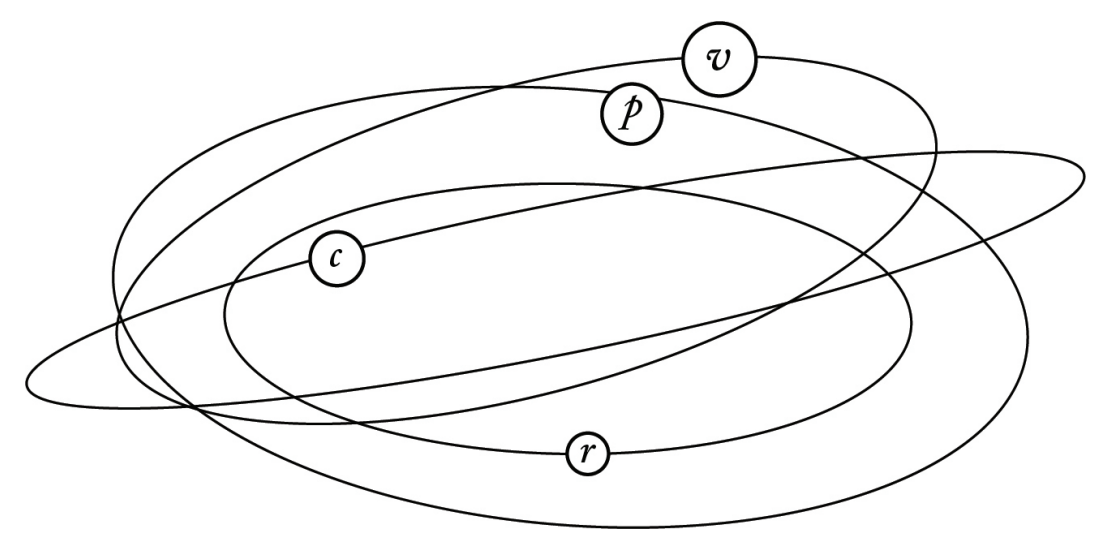


While our persistently geocentric imaginations can make it difficult, it's fruitful to imagine these bodies in orbit not as planets revolving around some single sun but, instead, as a group of suns orbiting one another-a type of constellation that we now know to be common throughout the universe. These celestial bodies vary in mass and age, and their trajectories are interconnected. For some questions, there are specific benefits to choosing gravity over polarity. Here I outline four ways that a gravitational model can help the analyst to think productively about persistent issues in the sociology of the arts.

First, this model promotes an emphasis on both practice and cultural change. Patterned changes in the relationships between different ideal types make a new kind of sense if the analyst imagines them existing not in stable opposition to one another but rather in slow, varying orbits together-sometimes accounts appear to be quite far from one another, but then they seem to meet and dance together for a moment or a generation. They are bodies in motion, and their movements are not random. Even the number of bodies in orbit is subject to change: on occasion new objects can be thrown into this gravitational relationship: isomorphic structures or other cultural debris can collide with, or splinter, or join one of the extant bodies. This metaphor allows for an image of cultural change that's both meaningful and, for actors, relatively legible: They have read their art history and their mentors made careers in a different age; they think that they see the future and where their field is headed. Artists and their activities, in this model, make sense through their relationships with these bodies in motion; their legibility is relational and contingent and historically specific, like in the real world.

Second, the gravitational model acknowledges and visualizes the ways that artists generally must manage overlapping but incommensurate forms of recognition, reputation, attention, and success. It can illuminate the issues represented by Bourdieu's y axis-consecration, success-in a new way, better modelling a field of diverse actors aiming simultaneously for multiple distinct but related forms of recognition, reputation, attention, and success. Here, artists and their activities can be seen to negotiate the four stars' gravitational pull (again, each sun representing an ideal type, an account of value), with the light reflected from each endowing the artist, practice, or artwork with diverse and varying kinds of success. At a given place and time, it will be likely that balancing a particular set of accounts will be more likely than other possibilities, given the changing configuration of accounts-two ideal types at one historical moment quite close together, at another moment distant and difficult to reconcile. This model reminds the analyst that accounts of value do not map neatly onto different sorts of people - instead, artists negotiate diverse accounts more or less constantly, working towards a color balance that will keep their practices and their selves safely illuminated in legitimacy and recognition. To extend the celestial metaphor, 
perhaps different parts of the spectrum, the varying lights thrown off by these stars, represent different types of consecration: the bright white of the visible spectrum bestowing those with success in the market a kind of glow, the heat of infrared light warming those beloved by the most avant-garde critics, the rare artists that balance both worlds successfully throwing off light and heat, at least for a moment.

Third, the persistent hegemony of an analytical focus on objects and their markets in both vernacular and sociological understandings of artistic practice makes a new kind of sense if we imagine it as deriving not from willful economism but from simpler issues of visibility and access. In this universe (as in our own), only small sections of the spectrum are visible to particular actors, and those sections seem to those actors to be the very definition of "light". With some effort and scientific equipment we can make the entire spectrum visible, but it might not change our subjective understanding and beliefs about the nature and reality of light-specialists, then, might have full access to the entire spectrum, but non-experts and those with less experience in art worlds will be unlikely to "see" all of the forms of recognition relevant to the art worlds they observe. What is more, they are unlikely to even know where to look-or to know that they should bother. We might acknowledge the objective existence of infrared light without expanding our vernacular definition of "light"; critical attention is nice, we say, but the market defines real success in the arts. In this model, artists that don't successfully navigate the space around these suns-artists that reflect no light at all-might be more or less invisible to the field no matter their activities, without the glow of widely shared accounts of value to illuminate the things that they do. This has clear methodological implications-does the analyst hope to study artists in terms of how those artists already appear to outsiders, or does the analyst hope to approach them on their own terms? For one of those questions, attention only to a small portion of the spectrum might be appropriate; for the other, mapping the spectrum in its entirety before considering strategies for selection may be necessary.

Finally, a gravitational model with its dense and hulking celestial bodies provides a corrective suggestion regarding questions of visibility and legitimacy central to understanding boundary formation and boundary work in creative fields-those thorny issues of one's "own work" and the issue of "quitting" in the arts. Artists that in a polar model could be viewed as "purely" autonomous- or heteronomous-pole artists are likely to be either delegitimized by or invisible to participants in art worlds, to the extent that they exist at all. A model that implies the mass required for gravitational pull makes it very easy to imagine how getting too close to a particular ideal type-failing to manage the relationship between diverse types, becoming a caricature-could result in a sudden exit from the 
field regardess of activity. Too much reliance on, to take one example, vocational accounts: the artist collides with the ideal type with all its dangers and caricatures; burning up, too close to the sun, their practice becomes invisible to the field and they become "just" a Sunday painter.

\section{Conclusion}

Binaristic traditions in the sociology of the arts, with their emphasis on art objects and their markets, are excellent to think with for analysts focused on objects in markets and actors as they act in relation to such objects. But such dualistic visions constrain our analytical leverage on broad and diverse artistic fields, artistic practice, and artistic identity. I have shown, using illustrative examples from a study of visual artists in the United States, how binaristic theoretical approaches conceal important features of art worlds, and have shown how an alternative model using another fundamental force-gravity, rather than the polarity of electromagnetism-can help the analyst to make sense of empirical data and generate new theoretically driven questions.

Throughout this article I have been careful to stay close to my own data-to act as if I am speaking only of visual artists-but of course this kind of model may be useful to those hoping to understand other occupational communities as well. A model such as this might be particularly productive if applied to others who engage in activities that have always been necessary and valued but only recently transformed, haltingly and imperfectly, into jobs and careers-think of the care of the young and others who require it, political work, religious work. In all of these arenas, as traditional forms of practice have undergone a partial occupational turn, questions of value - and related issues of quality, authority, and knowledgeare hard fought with diverse and divergent accounts of value, and understanding these communites may require moving beyond a market-focused binary.

This paper stems both from my own attempts to make sense of specific empirical puzzles-the issues of one's "own work" and of "quitting" in the arts serving as the illustrative puzzles here-but also because in my work with artists I have seen how the application of binary logics to the activities of everyday life often looks a lot more like the deployment of power and control than a good-faith attempt to understand, much less a prompt for positive change. Our beliefs about value-the stories we tell ourselves, and one another-have real, concrete ramifications.

We know that when we abstract from the world, we leave a lot of complexity aside in favor of theory-building and, we hope, greater understanding. Binaristic models of art worlds can serve as elegant representations of the market for objects, and help us to understand artists and their activities when they are oriented to 
that market. But most artists, most of the time, are doing other things. And those other things have their own patterns, make a different kind of sense. I have written elsewhere about one artist in particular and the real-world issues that can derive from dualistic thinking about value in the arts. In that work, I have traced the ways that state demands on artists to demonstrate a "profit motive" are motivated by inappropriate binaristic visions of artistic practice and shown how artists are doomed by both analytical and vernacular dualism in such contexts (Gerber 2014b).

Thinking in terms of gravity rather than the binarism so common in analyses of the arts helps us to understand things very differently, and can be especially useful in thinking about valuation beyond market value. Dualism is at the center of much of our social thought, and with it we often imply zero-sum games, economic logics, competition. But not everything is locked into dualistic battle, and normatively we might say that not everything should be understood through such binaristic visions. There's more to life than that, and there are other forces in the universe.

Alison Gerber is a postdoctoral researcher at the Department of Sociology at Lund University in Sweden focused on value, science, and public life. A book, The Work of Art: Value in Creative Careers, is out now from Stanford University Press. Alison holds a BA and BFA from the University of Minnesota, attended Critical Studies at Malmö Art Academy / Lund University, and holds an MA, MPhil, and $\mathrm{PhD}$ in Sociology from Yale University. She lives in Malmö, Sweden. E-mail: alison.gerber@soc.lu.se

\section{Notes}

1 I have chosen to engage with the Bourdieusian field as this article's foil, as it is absolutely central to North American and European sociological analyses of the arts. A very quick comparison on any bibliographic database shows that Bourdieu's central texts are more well cited than his closest competitors in terms best described as orders of magnitude. Therefore, while alternative and more recent perspectives can be highly generative (I am thinking here especially of excellent work by e.g. Childress 2017; Heinich 1996, 2012; Velthuis 2005), I have chosen to engage with a single and highly influential interlocutor for the purposes of this article rather than outline a tedious point-by-point discussion of the ramifications of each possible alternative.

2 I failed to schedule meetings with three artists, and a fourth was too ill to participate and died shortly after I asked for an interview.

3 The empirical material discussed here is highly condensed and paraphrased from other published peer-reviewed materials, and included only to the extent that it enables 


\section{Culture Unbound}

Journal of Current Cultural Research

the theoretical discussion to follow. Rather than citing myself endlessly, which I would find obnoxious, I will direct readers if they have a particular interest to the works that these illustrations are drawn from (Gerber 2014a, 2017). It has been difficult to find a balance between discussing previous work to the extent necessary to make a point and avoiding straightforward self-plagiarization; I hope that, given demands by reviewers that I recapitulate findings rather than citing sources, I have struck the right balance.

\section{References}

Abbott, Andrew (2005): "Ecologies and Fields." Retrieved September 14, 2017 (http://home.uchicago.edu/aabbott/Papers/BOURD.pdf).

Adams, Julia (2005): "The Rule of the Father: Patriarchy and Patrimonialism in Early Modern Europe." Pp. 237-66 in Max Weber's Economy and Society: A Critical Companion, edited by C. Camic, P. S. Gorski, and D. M. Trubek. Stanford University Press.

Alexander, Victoria D. \& Anne E. Bowler (2018): "Scandal and the Work of Art: The Nude in an Aesthetically Inflected Sociology of the Arts." Cultural Sociology 1749975518770283.

Biernacki, Richard. (1995): The Fabrication of Labor: Germany and Britain, 16401914. Berkeley: University of California Press.

Blanco, Patricia Prieto, Mirjami Schuppert \& Jake Lange (2015): "The Digital Progression of Community Archives, from Amateur Production to Artistic Practice: A Case Study of Belfast Exposed." Convergence 21(1):58-77.

de Boise, Sam (2016): "Post-Bourdieusian Moments and Methods in Music Sociology: Toward a Critical, Practice-Based Approach.” Cultural Sociology 10(2):17894.

Boltanski, Luc \& Laurent Thévenot (2006): On Justification: Economies of Worth. Princeton: Princeton University Press.

Bourdieu, Pierre (1983): "The Field of Cultural Production, or: The Economic World Reversed." Poetics 12(4-5):311-56.

Bourdieu, Pierre (1993): The Field of Cultural Production: Essays on Art and Literature. Cambridge, England: Polity Press.

Buchholz, Larissa. (2016): "What Is a Global Field? Theorizing Fields beyond the Nation-State." The Sociological Review Monographs 64(2):31-60.

Childress, Clayton (2017): Under the Cover: The Creation, Production, and Reception of a Novel. Princeton: Princeton University Press.

Gerber, Alison. (2014a): "Art Work?: Tradition, Rationalization, and the Valuation of Contemporary Artistic Practice.” Ph.D., Yale University, United States -- Connecticut.

Gerber, Alison (2014b): “The Audit of Venus." Berkeley Journal of Sociology 58(1):6-13.

Gerber, Alison (2017): The Work of Art: Value in Creative Careers. Palo Alto: Stanford University Press.

Gerber, Alison \& Clayton Childress (2017a): “I Don’t Make Objects, I Make Projects: Selling Things and Selling Selves in Contemporary Artmaking." Cultural Sociology 11(2):234-54.

Gerber, Alison \& Clayton Childress (2017b): "The Economic World Obverse: Freedom Through Markets After Arts Education." American Behavioral Scientist 61(12):1532-54

Heinich, Nathalie (1996): The Glory of Van Gogh: An Anthropology of Admiration. Princeton, N.J.: Princeton University Press.

Heinich, Nathalie (2012): "Mapping Intermediaries in Contemporary Art According to Pragmatic Sociology." European Journal of Cultural Studies 15(6):695-702.

Heise, Tatiana \& Andrew Tudor (2007): "Constructing (Film) Art: Bourdieu's Field Model in a Comparative Context." Cultural Sociology 1(2):165-87. 


\section{Culture Unbound}

Journal of Current Cultural Research

Hesmondhalgh, David (2006): "Bourdieu, the Media and Cultural Production." Media, Culture \& Society 28(2):211-31.

Howes, David (2005): "Introduction: Empires of the Senses." Pp. 1-17 in Empire of the Senses: The Sensual Culture Reader. Oxford: Berg.

Kharchenkova, Svetlana (2018): "The Market Metaphors: Making Sense of the Emerging Market for Contemporary Art in China." Poetics.

Klett, Joseph \& Alison Gerber (2014): "The Meaning of Indeterminacy: Noise Music as Performance." Cultural Sociology 8(3):275-90.

Krause, Monika (2018): "How Fields Vary." The British Journal of Sociology 69(1):3-22.

Lamont, Michèle (2012): "How Has Bourdieu Been Good to Think With? The Case of the United States." Sociological Forum 27(1):228-37.

Lamont, Michèle \& Virág Molnár (2002): "The Study of Boundaries in the Social Sciences." Annual Review of Sociology 28:167-95.

Lindström, Sofia (2017): "Be Creative: Making a Living in the New Culture Industries." International Journal of Cultural Policy 0(0):1-3.

Lund, Anna (2013): "Staging Gender: The Articulation of Tacit Gender Dimensions in Drama Classes in a Swedish Context." Gender and Education 25(7):907-22.

Malczewski, Eric (2016): "Materiality, Iconic Nature, and Albert Bierstadt's 'Great Pictures." American Journal of Cultural Sociology 4(3):359-84.

McKernan, Brian (2018): "Video Games, Contestation, and Meaning: A Strong Program Approach to Studying Artistic Legitimation." American Journal of Cultural Sociology 1-40.

Mears, Ashley (2011): Pricing Beauty: The Making of a Fashion Model. Berkeley, Calif. ; London: University of California Press.

Scarborough, Roscoe C. (2017): "Making It in a Cover Music Scene: Negotiating Artistic Identities in a 'Kmart-Level Market."' Sociological Inquiry 87(1):153-78.

Schwarz, Ori (2016): "The Sociology of Fancy-Schmancy: The Notion of 'Farterism' and Cultural Evaluation Under the Regime of Radical Suspicion." Cultural Sociology 1749975515627186.

Silver, Daniel (2018): "Figure It Out!" Sociological Methods \& Research 0049124118769089.

Snyder, Benjamin H. (2013): "From Vigilance to Busyness A Neo-Weberian Approach to Clock Time." Sociological Theory 31(3):243-66.

Solaroli, Marco. (2016): "The Rules of a Middle-Brow Art: Digital Production and Cultural Consecration in the Global Field of Professional Photojournalism." Poetics 59:50-66.

Stark, David. (2009): The Sense of Dissonance: Accounts of Worth in Economic Life. Princeton: Princeton University Press.

Swedberg, Richard (2016): "Can You Visualize Theory? On the Use of Visual Thinking in Theory Pictures, Theorizing Diagrams, and Visual Sketches." Sociological Theory 34(3):250-75.

Thompson, E. P. (1967): “Time, Work-Discipline, and Industrial Capitalism.” Past \& Present (38):56-97.

Thornton, Patricia H., William Ocasio \& Michael Lounsbury (2012): The Institutional Logics Perspective: A New Approach to Culture, Structure, and Process. OUP Oxford.

Velthuis, Olav (2005): Talking Prices: Symbolic Meanings of Prices on the Market for Contemporary Art. Princeton: Princeton University Press.

Weber, Max (1949): On the Methodology of the Social Sciences. Glencoe Ill: Free Press.

Weber, Max (2001): The Protestant Ethic and the Spirit of Captalism. London: Routledge.

Wohl, Hannah (2015): “Community Sense: The Cohesive Power of Aesthetic Judgment." Sociological Theory 33(4):299-326.

Zelizer, Viviana A. Rotman (2011): Economic Lives: How Culture Shapes the Economy. Princeton: Princeton University Press. 